\title{
SIVI NITTROJEN İLE SUNİ DOLU YAPIMI VE ŞIMDIYYE KADAR YAPILAN YAPAY DOLULARLA KARŞILAŞTIRILMASI
}

\author{
Gökalp YILMAZ ${ }^{1}$, Mehmet Eren UZ2 ${ }^{*}$, Mohammad DAWOOD SIZAR², Meryem Dilara KOP² \\ 1İnotim Mühendislik Makine San. ve Tic. A.Ş., AR-GE Sorumlusu, 09100, Aydın, Türkiye \\ ${ }^{2}$ Adnan Menderes Üniversitesi, Mühendislik Fakültesi, İnşaat Mühendisliği Bölümü, 09100, Aydın, Türkiye
}

\section{Anahtar Kelimeler $\quad$ Öz}

Dolu,

Sivi Nitrojen,

Yapay Dolu,

Dolu Darbe Testi.

Dolu, tanım olarak, donmuş katı bir şekilde yeryüzüne düşen su parçacıklarıdır. Boyutları 20 cm'ye kadar çıkabilmektedir. Bu sert kütleler yeryüzüne 80 ile 110 $\mathrm{km} / \mathrm{s}$ lik hızlarla çarpmakta, ancak bu çarpışmaya rağmen kırılmamaktadırlar. Doluların bu kütle ve hızlarda verdikleri zarar ise bir hayli fazladır. Örneğin; İspanya'nın Alicante şehrinde 2019'un Ağustos ayında gerçekleşen dolu firtınası 3 milyon euro değerinde zarar vermiştir. Araba kaportalarına, uçak gövdelerine, evlerin çatılarına, solar panellere, rüzgâr türbinlerine verdikleri zarar her yıl milyonlarca lira kayba neden olmaktadır. Tüm bunlara rağmen dolu ile ilgili çalışmalar, dolunun simüle edilememesi ve dolayısıyla dolunun verdiği hasarın da tam olarak simüle edilememesinden dolayı tam başarıya ulaştığı söylenememektedir. Bu çalışmada daha önceden yapılmamış ve literatüre geçmemiş olan sıvı nitrojen ve su ile suni dolu yapılmaktadır. Daha önceden dolu hasar testlerinde kullanılan çelik toplar, indentörler, normal buz küreleri gibi uygulamaların gerçeğe yakın sonuçlar vermediği ve dolu karakteristiği gösteremediği saptanmıştır. Bu eksiklik, yaptığımız "suni dolunun" gerçekle çok yakın karakterde olduğunun ispatı ile giderilmiștir. İșbu ispat dolunun kırılmaması, atış testlerinde benzer sonuçlar vermesi, suni dolunun yoğunluğu gibi parametrelerin gerçek doluya yakın olması sonucunda pekiștirilmiştir.

\section{PRODUCTION OF ARTIFICIAL HAILSTONE WITH LIQUID NITROGEN AND COMPARISONS WITH OTHER ARTIFICIAL HAILSTONES UP TO NOW}

\begin{tabular}{ll}
\hline Keywords & Abstract \\
$\begin{array}{l}\text { Hailstone, } \\
\text { Liquid Nitrogen, }\end{array}$ & Hailstones are, by definition, particles of water that fall into the Earth in a frozen \\
Artifial Hailstone, & solid. Its dimensions can be up to $20 \mathrm{~cm}$. These hard masses strike the Earth at speeds \\
Hailstone Impact Test. & of 80 to $110 \mathrm{~km} / \mathrm{h}$, but they do not break despite this collision. The damage caused \\
& by hail at this mass and speed is a great deal. For example, a hailstorm in August 2019 \\
& in Alicante, Spain, caused 3 million euros worth of damage. The damage they do to \\
& car bodywork, aircraft bodies, roofs of houses, solar panels, and wind turbines causes \\
& millions of Turkish liras of losses each year. In spite of all this, the studies related to \\
& hail cannot be said to have achieved full success due to the inability to simulate \\
& hailstones and therefore the damage caused by hailstones can not be fully simulated. \\
& In this study, artificial hailstones are made with liquid nitrogen and water, which \\
& have not been done before and have not been passed to the literature. It was \\
& determined that applications such as steel balls, indentors, normal ice spheres used \\
& in hail damage tests did not produce real results and did not show hail \\
characteristics. This deficiency has been eliminated by the proof that the "artificial & hailstones" we have made is very close to reality. This proof is confirmed as a result \\
of not breaking the hailstones, giving similar results in firing tests, and parameters \\
such as the density of the artificial hailstones being close to the actual hailstones.
\end{tabular}

\footnotetext{
* ilgili yazar / Corresponding author: mehmet.uz@adu.edu.tr, +90 (256) 2137503 - 3736
} 


\begin{tabular}{|c|c|c|}
\hline \multicolumn{3}{|l|}{ Alıntı / Cite } \\
\hline \multicolumn{3}{|c|}{$\begin{array}{l}\text { Yilmaz, G., Uz, M.E., Sizar, M.D., Kop, M.D., (2020). Sıvı Nitrojen ile Suni Dolu Yapımı ve Şimdiye Kadar Yapılan Yapay } \\
\text { Dolularla Karșılaștırılması, Mühendislik Bilimleri ve Tasarım Dergisi, 8(4), 1180-1189. }\end{array}$} \\
\hline Yazar Kimliği / Author ID (ORCID Number) & Makale Süreci / Article Process & \\
\hline $\begin{array}{l}\text { G. Yllmaz, } 0000-0003-2183-586 x \\
\text { M.E. Uz, 0000-0002-4466-5536 } \\
\text { M.D. Sizar, 0000-0003-3165-2346 } \\
\text { M.D. Kop, 0000-0001-6428-5744 }\end{array}$ & $\begin{array}{l}\text { Başvuru Tarihi / Submission Date } \\
\text { Revizyon Tarihi / Revision Date } \\
\text { Kabul Tarihi / Accepted Date } \\
\text { Yayım Tarihi / Published Date }\end{array}$ & \begin{tabular}{|l}
08.01 .2020 \\
21.09 .2020 \\
23.09 .2020 \\
25.12 .2020
\end{tabular} \\
\hline
\end{tabular}

\section{Giriş (Introduction)}

Dolu hasarı her yıl milyonlarca lira kayba neden olmaktadır. Dolu yağıșının hasarının önlenememesi geçmişten günümüze hep bir sorun olmuștur. İnsanları maddi ve manevi yönden kötü yönde etkileyen bu doğal afetin verdiği zararı azaltma amacı ile üniversiteler, özel laboratuvarlar, araba firmaları gibi kurumlar çalışmalar yapmaktadırlar. Yapılan çalışmalarda en önemli sorun ise gerçekçi bir dolu atışının elde edilememesidir. Bu sorunu, çözmek için ise önce doluyu simüle etmek gerekmektedir. Doluyu simüle edebilmek için farklı cisimlerle çalışmalar yapılmıştır. En çok kullanılan yöntem kalıp kullanılarak demineralize suyun dondurulması ile elde edilen yöntemdir. Plastik toplar (Flüerer vd. 2008), çelik toplar, normal buz küreleri gibi kullanılan cisimler doluyu simüle edememektedir. Doğal dolunun içten dişa donması, doğal dolunun embriyo adı verilen çekirdeğinde toz, tuz gibi malzemelerin bulunması doluyu oluşturan ve farklı kılan özelliklerdendir. Oysaki üstte sıralanan dolu yapım yöntemlerinde bunların hiçbiri yoktur. Araştırmalarımız sonucunda bulunan sıvı nitrojen kullanarak dolu üretme yöntemi, literatürüne girecek ve dolu testlerine sşık tutacak cinstendir. Literatürde bulunmaması da projenin özgünlüğü ve gelişe bilirliği açısından önemli niteliktedir.

\section{Kaynak Araştırması (Literature Survey)}

Bugüne kadar birçok farklı araştırmacı tarafından yapay dolu yapımı denenmiştir. Örnek olarak ilk olarak çelik ya da bașka indentör kullanılmıștır. (Johnson ve Schaffnit, 1973; Nomura vd., 1984;Vreede vd., 1995; Fleming vd., 1997; Shi vd., 1997; McCormick vd., 1998; USS, 2005; Flüeler vd., 2008). (Geoffrey Pyke vd., 1942) su-talaş karışımından buz yapmıştır. Swift (2013) pamuk kullanarak yapay dolu çalışmaları yapmıştır. Daha sonra Uz vd.(2017) \% 12 PVA (Polivinil Asetat) içeren dolularda deneyler yapmışlardır fakat bu yöntemlerin hiçbiri doğal dolunun oluşum sürecini ve özelliklerini göstermede yetersiz kalmaktadır fakat sıvı nitrojen kullanılarak yapılan dolu doğal dolunun oluşum sürecindeki gibi katmanlı oluşumu ve dolunun kırılmama özelliğini göstermektedir. $\mathrm{Bu}$ yöntem sayesinde literatürdeki bu eksiklik giderilmiş olacak ve daha sonra yapılacak çalışmalar için yol gösterici bir çalışma olacaktır.

\section{Materyal ve Yöntem (Material and Method)}

Doğal dolu Kümülonimbus adı verilen kümülüs bulutlarının dikey olarak gelişerek büyümesiyle oluşan konvektif firtına bulutlarındaki 0 ile -40 derece arasındaki sıcaklık farkından dolayı ani bir şekilde katman katman donar ve kristal bir yapıya sahip olur. Dolunun bu kristal yapısı doluya elastiklik katar ve güçlü olmasını sağlar. Lauri (1960) tarafından yapılan çalışmalar sonucunda dolunun merkezinde (çekirdeğinde) tuz, toz ve diğer partiküllerin de bulunduğu anlaşılmıştır.

"Dolu ile ilgili bu güne kadar yapılan çalışmalar, dolunun yapısı, oluşumu hakkında bizlere ışık tutmaktadır. Knight ve Knight (2016), dolu embriyoları, içerisinde hava kabarcıkları bulundurduğundan opak ve kristal yapıda göründüğünü belirtmektedirler. Çapı $5 \mathrm{~mm}$ 'den fazla olan buz yağışları Dunlop (2008) tarafındandolu olarak tanımlanmıştır. Ortalama dolu yoğunluğunun $0.91 \mathrm{~g} / \mathrm{cm}^{3}$ olduğu bildirilmiştir (Brimelow vd. 2002; Crenshaw ve Koontz 2002). Dolu boyutunun, dolu dayanımına etkisi Sain ve Narasimhan (2011)'ın yaptığı çalışmada belirtilmiştir. Knight ve Knight'ın belirttiği embryolarda donmuş olan hava kabarcıklarından dolayı embriyoların opak olması, Nelson'un (1983) dolu katmanları arasındaki opaklık farkının, kümülonimbus bulutlarındaki sıcaklık ve nem değișkenliği olduğunu ve opak katmanların su buharının ani donmasıyla oluştuğunu söylemiştir.

Swift(2013), pamuk kullanarak yaptığı çalıșmalarda,pamuklu buz küresinin dayanımınım normal buzdan fazla olduğunu göstermiştir. Gerektiğinden fazla dayanımdaki pamuklu dolu, homojen olmama, yüzey sürtünmesi farklılığı gibi problemleri bulunmaktadır.

Uz vd.'nin(2017) çalışmasında Dolu'nun karakteristik özelliklerinden şu şekilde belirtmiştir"illk olarak, dolu tanesinin büyük çoğunluğu buzdan oluşmalıdır. İkinci olarak, dolu tanesinin nitelikleri tanenin her yerinde aynı 
olmalıdır. Üçüncü olarak, üretilen dolu taneleri kullanılırken çarpışan yüzeyler arasında gerçekçi bir sürtünmenin simülasyonu için doğal dolu tanelerinde görülen yüzeyde erime davranışı görülmelidir. Son ve en önemli karakteristik özellik ise üretilen dolu tanelerinin hedeflenenlimit hızda isabet ettikten sonra bütünlüğünü korumalarıdır. Bu kriterlerin seçimi arkasındaki sebepler şunlardır: İlk kriter şu an kullanılan çelik ve plastik toplar gibi buzdan tamamen farklı davranan maddelerin kullanımından doğan belirsizlikleri kısıtlamaktadır.İkinci kriter, panel üzerinde oluşacak çukurun dolu tanesinin isabet ettiği yöne veya tanenin oryantasyonuna bağlı olarak değişmemesini sağlamaktadır. Üçüncü kriterin sebebi ise doğal dolu tanelerinin yeryüzüne düşerken sıcaklıktan dolayı yüzeyin eriyip ve böylelikle yüzey sürtünmesinin çok küçük bir değere çekilmesidir. Son olarak, en kuvvetli dolu taneleri bütünlüklerini limit hızda çarpışmadan sonra korumaktadır. Küçük parçalara ayrılan dolu taneleri parçalanma esnasında enerjiyi dağıtıp çelik panele aktarılan enerjiyi azaltacaktır."

Bu bulgular nazarında gerçekci bir dolu üretmek amacı ile önce yoğunluğunun sağlanması gerekmektedir. Daha sonra katman katman oluşması bu sayede yüksek dayanım gerekmektedir. Sonraki aşama ise çekirdek ve embriyo oluşumu sağlanmalı, gerçek doluya çok yakın olması sağlanmalıdır. Sıvı nitrojenin soğukluğu sayesinde bu dondurma işleminin adım adın gerçekleştirilebileceği öngörülmüş ve sıvı nitrojenle suni dolu üretme yöntemi yazar tarafından bulunmuş ve geliştirilmiștir.

\subsection{Literatürdeki Yapay Dolu Üretimi (Artificial Hailstone Production In Literature)}

Dünya'da yapılan dolu testlerinde birden fazla yöntem denenmiştir. En çok kullanılan yöntem demineralize su ile kalıplarda dondurma işlemidir, bunun yanında \%12 PVA (Polivinil Asetat) karışımlı, pamuk karışımlı, polyamide, çelik toplar, microfiber içerikli, talaş karışımlı kullanılmıştır. Dolu atış testlerinde kullanılan bu yapay dolularla yapılmıştır. Bazı araştırmacılar çelik ya da başka bir indentörü havadan serbest bırakarak denemeler yapmışlardır. [Johnson ve Schaffnit, 1973; Nomura vd., 1984;Vreede vd., 1995; Fleming vd., 1997; Shi vd., 1997; McCormick vd., 1998; USS, 2005; Flüeler vd., 2008.]. Geoffrey Pyke vd., 1942; su-talaş karışımından buz yapmış, dayanımını arttırmış ve adına Pykrete demiştir. Swift (2013) pamuk kullanımımın dolunun süneklil iğini arttırdığını söylemiştir. Daha sonra Uz vd.(2017) \% 12 PVA (Polivinil Asetat) içeren dolularda deneyler yapmışlardır. Bu çalışmalarda su ile karıştırılıp dondurulan buzların ortak özelliği ise dayanımlarının artmış olmasıdır. Bugüne kadar yapay dolu üretimi için kullanılan yöntemler Tablo 1'de verilmiştir.

Tablo 1. Yapay Dolu Üretiminde Kullanılan Yöntemler (Methods used in the production of artificial hail)

\begin{tabular}{|l|l|}
\hline Araştırmacılar & Kullandıkları Materyal \\
\hline $\begin{array}{l}\text { [Johnson ve Schaffnit, 1973; Nomura vd., 1984;Vreede vd., 1995; } \\
\text { Fleming vd., 1997; Shi vd., 1997; McCormick vd., 1998; USS, 2005; } \\
\text { Flüeler vd., 2008.] }\end{array}$ & Çelik ya da başka bir indentör \\
\hline Geoffrey Pyke & Su-talaş karışımından buz \\
\hline Swift (2013) & Pamuklu Dolu \\
\hline & \\
\hline Uz vd.(2017) & PVA'lı Dolu \\
\hline
\end{tabular}

Doluyu yapı ve teknik özelliksel yönleriyle simüle etmek için denenen bu yöntemler, dolunun bazı karakteristik özelliklerini gösterse de hepsini gösteremediği açıktır. Yapay doluyu üretmek büyük bir sorun olmuş ve olmaya da devam etmektedir. Günümüze kadar milyonlarca lira harcanarak yapılan dolu darbe testleri, bu kullanılan malzemelerle yapılmış ve güvenilir bir sonuca ulaşılamamıştır.

\subsection{Yapay Dolu Üretimi İçin Yeni Bir Yöntem: Sıvı Nitrojenli Dolu (A New Method For Artificial Hailstone Production: Hailstone With Liquid Nitrogen)}

Günümüze kadar yapılmaya çalıșılan suni dolulara, alternatif ve en güvenilir yeni bir yol olarak sıvı nitrojen dondurmalı dolu yapımı literatüre eklenecektir. Bu dolu tamamen doğal yollarla oluşturulup, bundan önce 
yapılan suni dolular gibi katkı maddeleri veya plastikler kullanılıp yapılmamıștır. Bu doluyu diğerlerinden ayıran unsurlardan bir tanesi de budur ama en önemli özelliği gerçek dolu gibi kırılmayıp katmansal bir yapıya sahip olmasıdır.

\subsubsection{Sıvı Nitrojen İle Suni Dolunun Oluşum Teorisi (Formation Theory Of Artificial Hailstone With Liquid Nitrogen)}

Dolu oluşumu, dikey bir bulut olan kümülonimbus bulutlarında gerçekleşmektedir. Bu bulutlar dikey olarak kümülüs bulutlarının büyümesiyle oluşmaktadır. İçlerinde dolu, fırtına ve elektrik yükü (şimşek) bulundurmaktadırlar ve bu durumdan dolayı hava araçları da bu bulutların içine girmekten kaçınmaktadır. Dikey bu bulutların içinde sert hava akımları olmaktadır. Ayrıca bu bulutlar dikey konumlarından dolayı taban ve tavan arasında sıcaklık farkına sahiptir. Dolunun oluşumu bu ani hava akımı ve ani değișen sıcaklıklarla olmaktadır. Dolu Lauri'nin(1960) makalesinde belirttiği gibi toz, tuz gibi partüküllere su buharının tutunmasıyla başlamaktadır ve bu partikül dolunun embryosu olarak adlandırılmaktadır. Katman Katman donan ve taban ile tavan arasında gidip gelen parçacıklar birbirine tutunmakta ve ağırlaşmaktadır. Bulutun içindeki hava akımının kaldırma kuvvetinden daha fazla ağırlığa sahip olduklarında ise Şekil 1'deki gibi yeryüzüne düşerler.

Kümülonimbus bulutlarında gerçekleşen su buharının ve damlacıklarının ani donma olayını laboratuvar ortamında gerçekleştirmek gereksinimi tespit edilmiştir. Anlatılan bu olayı ve sıcaklık farklılığındaki donmayı simüle etmek için Aydın Adnan Menderes Üniversitesi Dolu Laboratuvarında bir dizi araştırmalar ve denemeler yapılmıştır. Kümülonimbus bulutlarında gerçekleşen bu hava olayını Laboratuvar şartlarında yapmak için çalışmalara ve alt yapı oluşturulmaya başlanmıştır. Bu çalışma için çok soğuk bir malzemeye (minimum $-40^{\circ} \mathrm{C}$ ) ve $+0^{\circ} \mathrm{C}$ derecede suya ihtiyaç vardır. Negatif derecedeki malzeme için sıvı nitrojenin simule edileceği öngörülmüştür. Bunun için dewar kabı ve sıvı nitrojen tedarik edilmiştir. Ayrıca dolunun tutunacağı bir embryo oluşturulması gerekmetedir. Bunun için bir çeşit ipin ucuna ufak bir düğüm atarak bu embryonun oluşturulması düşünülmüştür. Bu uygulama teorisinde, Kümülonimbus bulutunda oluşan dolunun embryosu ip düğümü, bulutun tavanı sıvı nitrojen tabanı ise $+0^{\circ} \mathrm{C}$ su olarak eşlenmiştir. Bu sayede aynı Kumulonimbus bulutlarındaki gibi suyun katman katman ve ani bir șekilde donmasını sağlayacaktır. Ayrıca ani donma su partiküllerinin kristal etkisi gösterip kırılmama özeliğini de arttıracaktır.

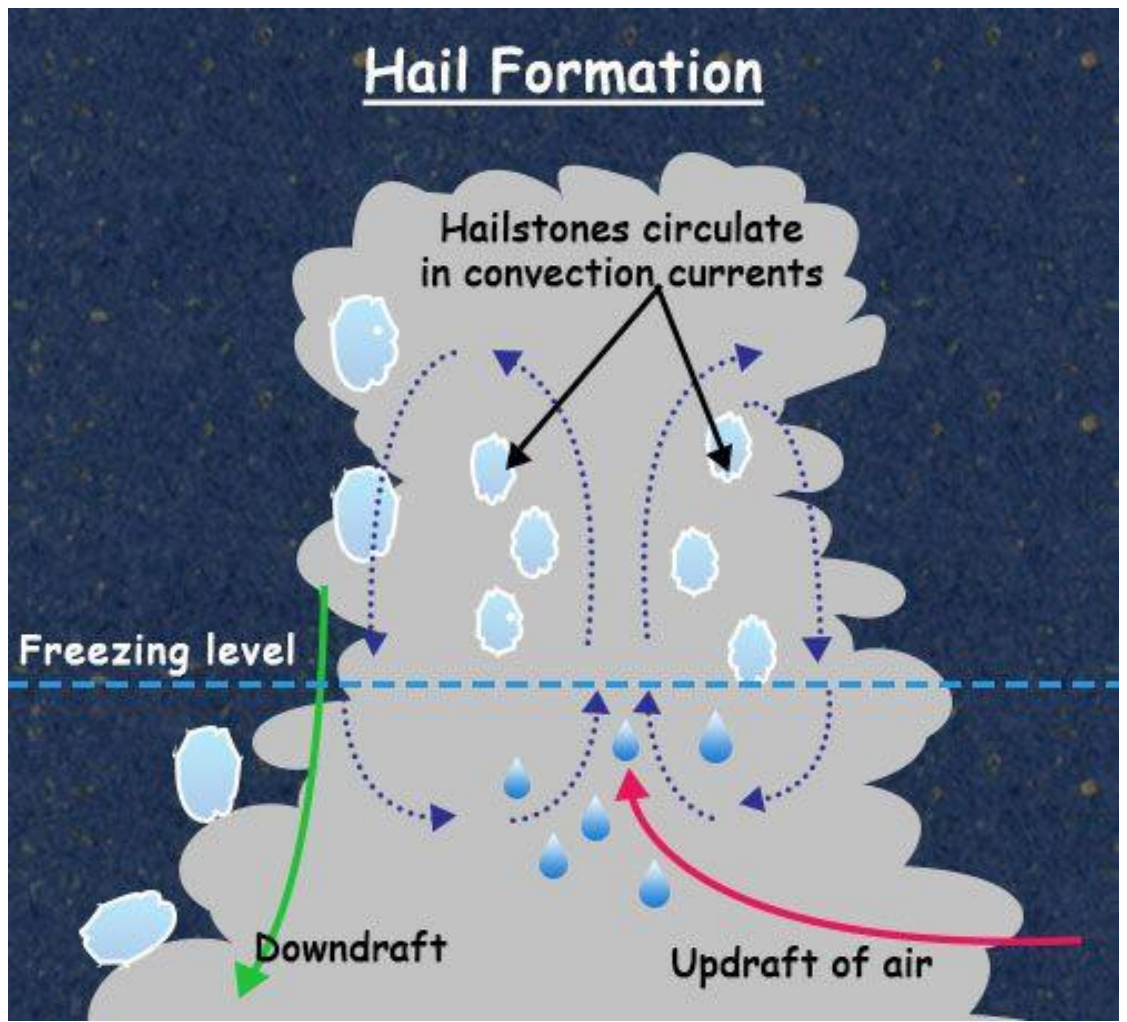

Şekil 2. Dolu oluşum anlatımı ve kümülonimbus bulutu (Hail formation and cumulonimbus cloud) 


\subsection{Sıvı Nitrojen İle Suni Dolunun Laboratuvarda Oluşturulması ve Kullanılan Malzemeler (Forming artificial hailstone with liquid nitrogen in the laboratory and materials used)}

Azot (sıvı nitrojen): kimyasal simgesi "N" olan ametal bir elementtir. Doğada serbest azot iki atomlu "molekül halinde" bulunduğundan dolayı " $\mathrm{N}_{2}$ " olarak simgelenir. Sıvı nitrojenin bazı fiziksel özellikleri şunlardır: Maddenin hâli gaz, sıvı hâldeki yoğunluğu $0,808 \mathrm{~g} / \mathrm{cm}^{3}$, kaynama noktası $-196^{\circ} \mathrm{C}$ derece ve erime noktası $-210^{\circ} \mathrm{C}$ derecedir. Şekil 2 de görülen malzemeler ile dolu yapımı gerçekleşmiştir.

Saf su: Saf su denildiğinde aklımızda ilk etapta temiz su gelmektedir, fakat bu düşünce yanlıştır. Su, iki hidrojen ve bir oksijen atomundan meydana gelmektedir. Ancak bunun yanı sıra içerisinde kalsiyum, magnezyum, bikarbonat gibi mineraller dâhil farklı maddeler de yer almaktadır. Saf su ise, suyun içerisindeki bu minerallerin ve maddelerin, farklı kimyasal süreçlerden geçirilerek ve genellikle $80^{\circ} \mathrm{C}$ dereceye kadar ısıtılan suyun buharının yoğunlaştırılarak ayrı bir kaba aktarılmasıyla elde edilmektedir. $\mathrm{Bu}$ çalışmada saf suyun kullanılmasının nedeni ise bulutlardaki su parçacıklarına yakın olmasıdır. Yaptığımız çalışmada $4^{\circ} \mathrm{C}$ derecelik saf su kullanılmıştır. Ayrıca yağmur suyu yeryüzüne düşerken havadaki partiküllerin karışmasıyla saf su özelliğini kaybetmektedir. Bundan dolayı yağmur suyu, musluk suyu, doğal kaynak suyu gibi sular kullanılmamıștır. Bulutlarda bulunan su buharının yoğunlaşmasında ortaya çıkan su, yeryüzünde en yakın olarak laboratuvar şartlarında üretilen saf suya eş çıkmaktadır.

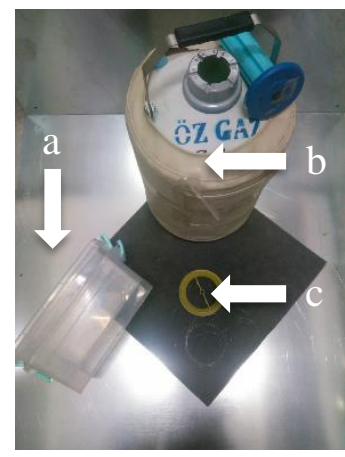
a) Su Kapları
b) Dewar Kabı
c) Misina

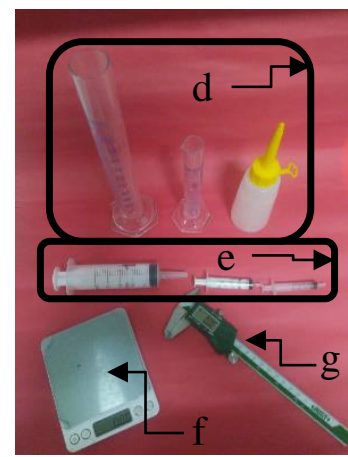

d) Dereceli Silindirler

e) Şırıngalar

f) Hassas Terazi

g) Kumpas

Şekil 2. Sıvı nitrojenli dolu yapımında kullanılan materyaller (Materials used for making of liquid nitrogen hail)

Sıvı Nitrojen Tankı ve Dewar Kabı: Sıvı nitrojenin çevresel faktörlerden etkilenmeden ve kolayca taşınılabilmesi için gereken sıvı nitrojen tankı sayesinde, sıvı nitrojen buharlaşmadan ve tehlikeli durumları engelleyerek saklanmaktadır. Dewar kabına, sıvı nitrojen tankından aktarılan, sıvı nitrojen sayesinde dewar kabı üzerinde çalışma yapılabilmektedir.

Saf su Tankı ve Su kapları: Saf su tankı sayesinde kullanacağımız saf suyun bozulmasının engellenmesi ve sonuçların ideale yakın çıkması hedeflenmiştir. Su kapları ise dewar içindeki sıvı nitrojen ve suyun daldırma işleminde sürekliliğini sağlayacaktır.

Misina ve Daldırma Düzeneği: Misina, dolu içerisinde bulunan "dolunun çekirdeği" adı verilen kısım görevini görecek ve su tutarak, dolu yağışlarına neden olan Kümülonimbus bulutlarının içerisindeki durumu simüle edecektir. Misinanın bağlı olduğu daldırma düzeneği ise, bir seferde daha fazla dolunun ortaya çıkmasını ve kullanım kolaylığı sağlayacaktır.

Dolu Atış Silahı ve Atış Testleri: Bir pnömatik atıcı, yüksek basınca dayanıklı hava tankı, hava kesici, namlu, hızölçer sensörler, yüksek hızlı kamera, barometre ve kompresörün bulunduğu Şekil 2'de gösterilen dolu atış silahı sayesinde, çap ve kütleleri ölçülmüş, yoğunlukları hesaplanıp numaralandırılmış olan Suni dolular, farklı kalınlıktaki çatı panellerine atılmaktadır.

Şekil 3'deki sitemde kompresörden çıkan hava, yüksek basınca dayanıklı hava tankına dolmaktadır. Bu tank içerisinde bulunan havanın basıncı barometre yardımıyla kontrol edilmektedir. Basınç 3 ile 3.5 bar arasında olduğunda pnömatik kesici buton ile devre dışı bırakılarak basınçlı hava namludan çıkmaktadır. Namlunun içerisine koyulan suni dolu bu hava basıncı ile çapına ve ortam koşullarına bağlı olarak 70-110 km/s hızlarda Koruma kafesi içerisindeki plakaya çarpmaktadır. Bu çarpışma sonucunda oluşan çukur, dolu hasarını, dolunun 
durumu ise dolu dayanımını temsil etmektedir. Suni dolunun namludan levhaya çarpana kadar olan hızı ise hız sensörü ve yüksek hızlı kamera ile ikili olarak ölçülüp teyit edilmektedir. Namlu ile levha arasında 1 metre mesafe bulunmakta ve testler bu șekilde yapılmaktadır.

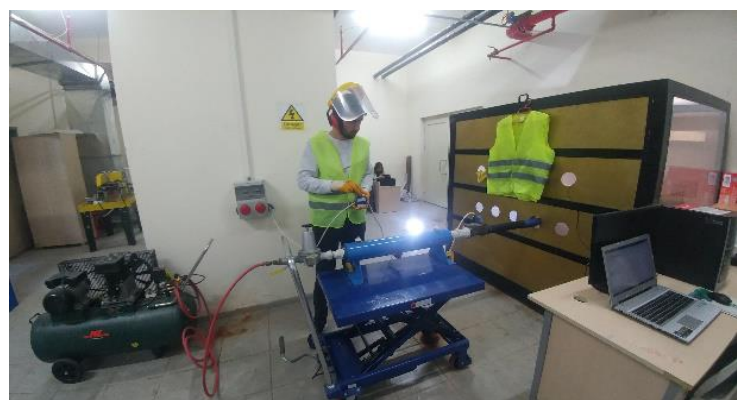

Şekil 3. ADÜ dolu atış test laboratuvarı (ADU - Hailstone test laboratory)

\subsection{Sıvı Nitrojenli Dolu Yapımı (Liquid Nitrogen Hailstone Construction)}

Nitrojenli Dolu yapımında iki adet kap kullanılmaktadır. Bu kaplardan bir tanesi saf su ile doldurulmaktadır. Diğer kap ise dewar kabıdır ve içine sıvı nitrojen konulmaktadır. Misinanın ucuna nitrojen ve su toplanması için dügüm atılır ve bu işlem sayesinde doğal dolu yapısında bulunan "dolu çekirdeği" simüle edilmektedir. Bu ișlemden sonra saf suya batırılan düğüm atılmıs misina dewar kabındaki sıvı nitrojen içine daldırılarak suyun ani bir şekilde donması sağlanmaktadır. Bu uygulamanın amacı doğal dolunun yapısındaki gibi katmanlı bir şekilde donması sağlamaktır. Sıvı nitrojenli dolu yapımının diğer suni dolu yapım yöntemlerinden farklı ve en önemli ayırt edici özelliği de budur. Daldırma işlemleri dolu istenilen çapa gelinceye kadar tekrarlanmaktadır. Misina daldırılan suyun doğal doludaki sıcaklık değerine yakın olması için saf suyun içine buz konulmaktadır. $\mathrm{Bu}$ işlem yapılarak kümülonimbus bulutlarında 0 ile -40 derece olan sıcaklık farkını simüle etmektedir.

\section{Deneysel Sonuçlar (Experimental Results)}

Dolu atış testleri ve analizlerinde kullanılan suni dolularla sıvı nitrojen kullanılarak yapılan dolunun karakteristik özelliklerinin karşılaştırılması Tablo 2'de verilmiştir.

Tablo 2. Çalışmalarda Kullanılan Suni Doluların Gerçek Dolunun Karakteristik Özellikleri ile Karşılaştırılması (Comparison of artificial hailstones used in studies with the characteristic features of Real hailstones)

\begin{tabular}{|l|c|c|c|c|}
\hline & Yoğunluk $\left(\mathrm{g} / \mathrm{cm}^{3}\right)$ & Kristal Yapı & Kırılmama & Katmanlı yapı \\
\hline Çelik Top & $\mathrm{X}$ & $\mathrm{X}$ & $\boldsymbol{V}$ & $\mathrm{X}$ \\
\hline Saf sulu Dolu & $\boldsymbol{V}$ & $\mathrm{X}$ & $\mathrm{X}$ & $\mathrm{X}$ \\
\hline PVA'lı Dolu & $\boldsymbol{V}$ & $\mathrm{X}$ & $\boldsymbol{V}$ & $\mathrm{X}$ \\
\hline Nitrojenli Dolu & $\boldsymbol{V}$ & $\boldsymbol{V}$ & $\boldsymbol{V}$ & $\boldsymbol{V}$ \\
\hline Gerçek Dolu & $\boldsymbol{V}$ & $\boldsymbol{V}$ & $\boldsymbol{V}$ & $\boldsymbol{V}$ \\
\hline Pamuklu Dolu & $\boldsymbol{V}$ & $\mathrm{X}$ & $\boldsymbol{V}$ & $\mathrm{X}$ \\
\hline
\end{tabular}

Sıvı nitrojen kullanılarak yapılan dolunun yoğunluk hız ve kırılma açısından test sonuçlarının değerlendirilmesi Tablo 3'de verilmiştir. PVA'lı dolu ile yapılan atış sonuçları kamera ve sensörde ölçülen hızları ve atış sonrası durumu Tablo 4'te yapay dolu üretiminde kullanılan yöntemler de verilmiștir.

$\mathrm{Bu}$ çalışmanın önemi sıvı nitrojen kullanılarak yapılan dolunun doğal dolunun kırılmama karakteristiğini gösterdiğini kanıtlamasıdır. Bu çalışmada 5 adet kırılan 5 adet kırılmayan dolunun bulunması çalışmanın seyri açısından çok önemlidir. Doluyu simule etmenin en önemli özelliği kırılmamasıdır ve bu kırılmama dolu deneylerinde ancak çelik top, pamuklu buz gibi materyallerle sağlanılmaya çalışılmaktadır ki bu testler dolu karakteristiği göstermedikleri için bașarılı sonuçlar verememiștirler. En yakın olarak PVA bazlı Dolu kullanılmıştır. Sıvı nitrojen ile yapılan testlerde en iyi sonucu sıvı nitrojenli dolunun verdiği gözlemlenmiştir.

Sıvı nitrojen kullanılarak yapılan dolunun ve diğer suni doluların kesitleri Șekil 4'te verilmektedir. Bu kesit alanları doluların iç kısımlarının nasıl oluştuğuna dair bizlere önemli bilgiler vermektedir. Ayrıca doğal doluda oluşan katmansal yapının sıvı nitrojenli suni doluda da gözlemlenebildiğini göstermektedir. 
Tablo 3. Sıvı Nitrojen Dondurmalı Dolunun Yoğunluk, Hız ve Atış Sonrası Durumları (Density, speed and situation of liquid nitrogen freeze hailstone after impact)

\begin{tabular}{|c|c|c|c|c|c|}
\hline \multirow{2}{*}{$\begin{array}{c}\text { Atış } \\
\text { Numarası }\end{array}$} & \multirow{2}{*}{$\begin{array}{l}\text { Dolu Çapı } \\
\text { (mm) }\end{array}$} & \multirow{2}{*}{$\begin{array}{l}\text { Yoğunluk } \\
\left(\mathrm{g} / \mathrm{cm}^{3}\right)\end{array}$} & \multicolumn{2}{|c|}{ Hiz (m/s) } & \multirow{2}{*}{$\begin{array}{c}\text { Atış Sonrası Dolu } \\
\text { Durumu }\end{array}$} \\
\hline & & & Kamera & Sensör & \\
\hline 1 & 41.98 & 1084.24 & 25.71 & 24.77 & Kırıldı \\
\hline 2 & 44.94 & 1077.63 & 27.41 & 23.32 & Kırılmadı \\
\hline 3 & 47.63 & 1049.86 & 30.56 & 26.11 & Kırıldı \\
\hline 4 & 48.99 & 1163.03 & 28.29 & 23.37 & Kırıldı \\
\hline 5 & 49.25 & 989.83 & 25.47 & 22.52 & Kırılmadı \\
\hline 6 & 48.02 & 1012.24 & 28.48 & 27.72 & Kırılmadı \\
\hline 7 & 46.37 & 1088.02 & 29.17 & 24.81 & Kırıldı \\
\hline 8 & 48.15 & 997.63 & 29.59 & 26.47 & Kırılmadı \\
\hline 9 & 48.84 & 996.53 & 31.06 & 33.86 & Kırılmadı \\
\hline 10 & 49.21 & 934.54 & 28.18 & 27.05 & Kırıldı \\
\hline
\end{tabular}

Tablo 4. PVA'lı Dolunun Yoğunluk, Hız ve Atış sonrası Durumları (Density, speed and situation of PVA hailstone after

\begin{tabular}{|c|c|c|c|c|c|}
\hline \multirow{2}{*}{$\begin{array}{c}\text { Atış } \\
\text { Numarası }\end{array}$} & \multirow{2}{*}{$\begin{array}{l}\text { Dolu Çapı } \\
(\mathrm{mm})\end{array}$} & \multirow{2}{*}{$\begin{array}{l}\text { Yoğunluk } \\
\left(\mathrm{g} / \mathrm{cm}^{3}\right)\end{array}$} & \multicolumn{2}{|c|}{ Hiz (m/s) } & \multirow{2}{*}{ Atış Sonrası Dolu Durumu } \\
\hline & & & Kamera & Sensör & \\
\hline 1 & 49.86 & 990.53 & 29.41 & 31.79 & Kırılmadı \\
\hline 2 & 50.58 & 953.45 & 31.93 & 31.47 & Kırılmadı \\
\hline 3 & 37.79 & 994.44 & 27.34 & 30.06 & Doluda Hafif kırık oluştu \\
\hline 4 & 37.21 & 1011.74 & 27.5 & 29.52 & Kırıldı \\
\hline 5 & 37.57 & 1026.41 & 30.92 & 27.05 & Kırıldı \\
\hline 6 & 44.51 & 1002.56 & 30.48 & 31.94 & Kırıldı \\
\hline 7 & 44.88 & 982.42 & 31.99 & 31.83 & Kırıldı \\
\hline 8 & 44.22 & 1009.62 & 30 & 28.39 & Kırıldı \\
\hline 9 & 44.65 & 971.71 & 30.87 & 31.56 & Kırıldı \\
\hline 10 & 44.96 & 964.36 & 28.33 & 31.94 & Kırılmadı \\
\hline
\end{tabular}

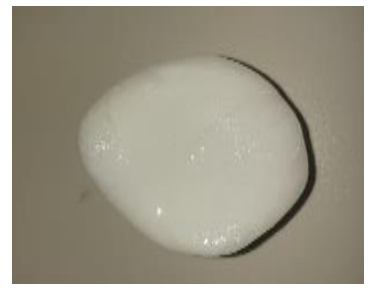

a) \%12'lik PVA'lı dolu

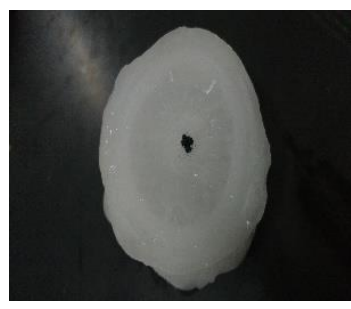

c) Sıvı nitrojenli dolu

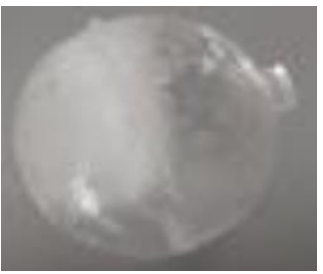

b) Saf su ile dolu

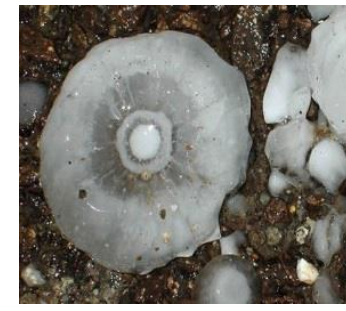

d) Doğal dolu

Şekil 4. Kullanılan bazı suni doluların ve gerçek dolunun kesit alanı (Cross-sectional area of some used artificial hail and real Hail) 
Şekil 5'te doğal dolu ve nitrojenli dolunun çekirdeği ve embriyo kısımları verilmiştir. Şekil 5 oluşum açısından birbirlerine benzerliklerini göstermektedir. Bu benzerlik doğal dolunun bir diğer ayırt edici özelliği olan çekirdek-embriyo yapı ikilemesinin sıvı nitrojenli doluda oluştuğunu da ispatlamaktadır.

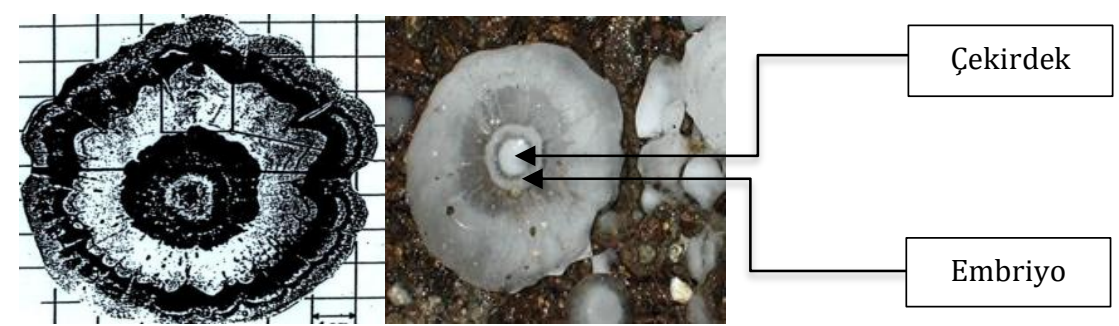

a) Doğal Dolu Çekirdek ve Embryoları

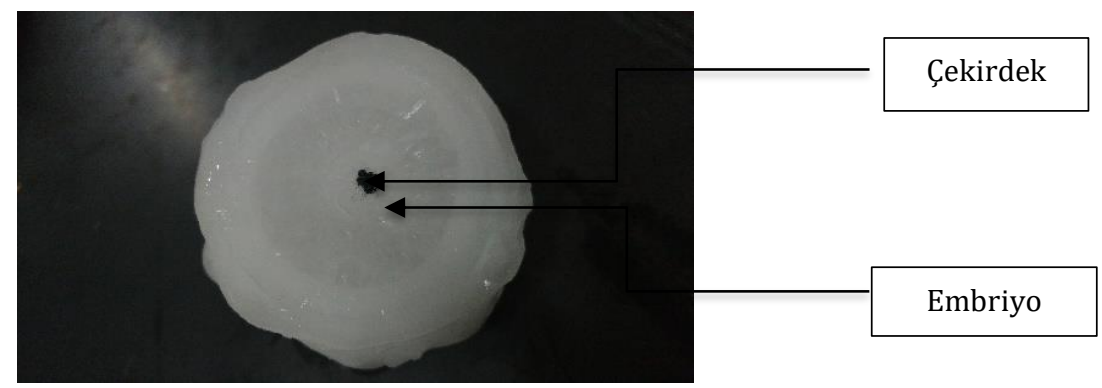

b) Sıvı Nitrojenli Dolu Kesit Alanı

Şekil 5. Sıvı nitrojen dondurmalı dolu ve gerçek dolunun iç kısımlarının görsel olarak karşılaştırılması (A visual comparison of the inner parts of the liquid nitrogen freeze hail and the real hail)

\section{Sonuç ve Tartışma (Result and Discussion)}

Yaptığımız bu çalışmada azotlu dolu ile 40 adet atış desti yapılmıştır. Bu atış testinde kullanılan doluların çapı 40 ile $50 \mathrm{~mm}$ arasında değişmektedir. Ayrıca yapılan bu atış deneylerinde dört farklı kalınlıkta sahip olan çelik plakalar kullanılmıştır. Kullanılan çelik levhaların kalınlığı; 0.30, 0.45, 0.60 ve 0.7 mm'dir ve atışlardan elde edilen sonuçlar Tablo 5’te verilmiştir.

Tablo 5'te yapılan çalışmalarda, nitrojen ile dondurulan suni dolular farklı kalınlıklardaki plakalara atılmış, hız,yoğunlukluk ve kırılım durumları gözlemlenmiştir. Testler neticesinde, imal edilen suni dolunun $0.3 \mathrm{~mm}, 0.45$ $\mathrm{mm}$ ve $0.6 \mathrm{~mm}$ kalınlıklarda daha iyi performans gösterdiği, $0.7 \mathrm{~mm}$ kalınlıktaki plakada ise daha düşük performans gösterdiği gözlemlenmiştir.

Dolunun aynı şartlarda farklı kırılım davranışları göstermesinin sebebi, el ile manuel bir şekilde suni dolu oluşturulmasından kaynaklı; sıcaklık, tozlaşma, bekleme süresi gibi çevresel faktörlerden kaynaklandığı düşünülmektedir. Bu sorunun üstesinden gelmek standart bir dolu üretimi yapmak için 0oC de oda, otomatik dolu üretim makinası gibi AR-GE faaliyetleri gibi çalışmalar sürmektedir.Doğal dolu farklı çaplarda meydana gelerek günlük hayatta birçok maddi ve can kayıplarına sebep olmaktadır. Dolunun Yoğunluk, kristal yapısı, katmanasal yapı ve diğer karakteristik özellikleri vardır. Bu çalışmaya kadar birçok araştırmacı farklı malzemeler ve birbirinden farklı yöntemler kullanarak yapay dolu üretip çarpma deneyleri yapmışlardır. Fakat bu çalışmalar dolunun karakteristik özelliklerinin hepsini göstermede yetersiz kalmıştır. Tablo 3'te verilen Sıvı Nitrojenli dolu ile Tablo 4'teki PVA'lı (Polivinil Asetat) dolunun yapılan deney sonuçlarını göz önüne alırsak, sıvı nitrojen kullanarak yapılan dolunun Yoğunluğu, kristal yapısı, katmansal bir yapıya sahip olması ve yapılan çarpma deneyleri sonucunda kırılmama özelliğini PVA’lı (Polivinil Asetat) doluya göre daha iyi sonuç sağlayarak literatürdeki bu eksikliği gidermektedir. Bu çalışma sayesinde, dolu testlerinde yeni ve güvenilir bir yöntem ortaya çıkmıştır. Daha sonra yapılacak çalışmalar için diğer araştırmacılara yol gösterici bir çalışma niteliğindedir. 
Tablo 5. Sıvı azotlu dolunun deneyde elde edilen verileri (Data of liquid nitrogen hailstone obtained in the experiment)

\begin{tabular}{|c|c|c|c|c|c|c|c|}
\hline \multirow{2}{*}{ Atış No } & \multirow{2}{*}{$\begin{array}{l}\text { Plaka } \\
\text { Kalınlığı } \\
\text { (mm) }\end{array}$} & \multirow{2}{*}{$\begin{array}{c}\text { Dolunun } \\
\text { Çapı } \\
\text { (mm) }\end{array}$} & \multirow{2}{*}{$\begin{array}{c}\text { Atış } \\
\text { Basıncı } \\
\text { (bar) }\end{array}$} & \multirow{2}{*}{$\begin{array}{c}\text { Dolunun } \\
\text { Yoğunluğu } \\
\text { (g/cm3) }\end{array}$} & \multicolumn{2}{|c|}{$\operatorname{Atış~Hızı~(m/s)~}$} & \multirow{2}{*}{$\begin{array}{c}\text { Atış Sonrası } \\
\text { Dolunun Durumu }\end{array}$} \\
\hline & & & & & Sensör & Kamera & \\
\hline 1 & 0.3 & 46.483 & 3.2 & 1007.826 & 28.51 & 24.52 & Sağlam \\
\hline 2 & 0.3 & 46.937 & 3.3 & 938.271 & 29.38 & 29.12 & Kırıldı \\
\hline 3 & 0.3 & 47.287 & 3.3 & 979.004 & 34.65 & 29.12 & Sağlam \\
\hline 4 & 0.3 & 47.910 & 3.3 & 927.394 & 32.37 & 28.55 & Üçe Kırıldı \\
\hline 5 & 0.3 & 48.903 & 3.3 & 955.305 & 25.13 & 25.76 & Sağlam \\
\hline 6 & 0.3 & 47.430 & 3.3 & 971.945 & 22.98 & 22.54 & Kırıldı \\
\hline 7 & 0.3 & 46.153 & 3.3 & 949.951 & 40.09 & 33.56 & Sağlam \\
\hline 8 & 0.3 & 49.443 & 3.3 & 924.345 & 32.78 & 31.56 & İkiye Kırıldı \\
\hline 9 & 0.3 & 46.670 & 3.3 & 963.841 & 27.82 & 24.42 & Üçe Kırıldı \\
\hline 10 & 0.3 & 49.093 & 3.3 & 966.853 & 23.32 & 23.48 & Kırıldı \\
\hline 11 & 0.45 & 48.103 & 3.2 & 990.038 & 20.90 & 21.04 & Üçe Kırıldı \\
\hline 12 & 0.45 & 47.753 & 3.4 & 989.167 & 34.15 & 33.06 & Kırıldı \\
\hline 13 & 0.45 & 49.187 & 3.3 & 969.385 & 32.59 & 29.48 & Kırıldı \\
\hline 14 & 0.45 & 46.343 & 3.3 & 1053.445 & 26.08 & 27.91 & Sağlam \\
\hline 15 & 0.45 & 48.723 & 3.3 & 969.234 & 37.72 & 31.94 & İkiye Kırıldı \\
\hline 16 & 0.45 & 46.143 & 3.3 & 1006.942 & 27.49 & 31.00 & Üçe Kırıldı \\
\hline 17 & 0.45 & 47.097 & 3.2 & 996.385 & 24.19 & 26.52 & İkiye Kırıldı \\
\hline 18 & 0.45 & 47.687 & 3.2 & 938.723 & 46.94 & 23.29 & Sağlam \\
\hline 19 & 0.45 & 49.337 & 3.3 & 1005.099 & 111.43 & 31.13 & İkiye Kırıldı \\
\hline 20 & 0.45 & 48.067 & 3.3 & 975.107 & 25.07 & 28.05 & Üçe Kırıldı \\
\hline 21 & 0.6 & 41.980 & 3 & 1084.235 & 24.77 & 25.71 & Kırıldı \\
\hline 22 & 0.6 & 44.937 & 3.1 & 1077.628 & 23.32 & 27.41 & Sağlam \\
\hline 23 & 0.6 & 47.633 & 3.3 & 1049.852 & 26.11 & 30.56 & Kırıldı \\
\hline 24 & 0.6 & 48.990 & 3 & 1163.033 & 23.37 & 28.29 & Kırıldı \\
\hline 25 & 0.6 & 49.247 & 3.2 & 989.832 & 22.52 & 25.47 & Hafif Hasar \\
\hline 26 & 0.6 & 48.023 & 3.3 & 1012.238 & 27.72 & 28.48 & Sağlam \\
\hline 27 & 0.6 & 46.370 & 3.3 & 1088.024 & 24.81 & 29.17 & Üçe Kırıldı \\
\hline 28 & 0.6 & 48.147 & 3.4 & 997.634 & 26.47 & 29.59 & Sağlam \\
\hline 29 & 0.6 & 48.843 & 3.4 & 996.527 & 33.86 & 31.06 & Hafif Hasar oluştu \\
\hline 30 & 0.6 & 49.207 & 3.4 & 934.540 & 27.05 & 28.18 & Kırıldı \\
\hline 31 & 0.7 & 47.210 & 3.3 & 981.966 & 34.51 & 35.96 & Kırıldı \\
\hline 32 & 0.7 & 47.443 & 3.2 & 989.011 & 25.16 & 28.29 & Üçe Kırıldı \\
\hline 33 & 0.7 & 49.630 & 3.2 & 978.009 & 28.98 & 28.29 & Kırıldı \\
\hline 34 & 0.7 & 48.233 & 3.2 & 937.802 & 26.90 & 26.77 & Kırıldı \\
\hline 35 & 0.7 & 48.250 & 3.2 & 964.034 & 28.61 & 26.05 & Kırıldı \\
\hline 36 & 0.7 & 47.343 & 3.3 & 1027.687 & 34.15 & 29.22 & Kırıldı \\
\hline 37 & 0.7 & 45.247 & 3.3 & 1032.950 & 39.59 & 36.99 & Kırıldı \\
\hline 38 & 0.7 & 47.037 & 3.1 & 994.698 & 23.66 & 23.67 & Kırıldı \\
\hline 39 & 0.7 & 47.197 & 3.2 & 1017.315 & 30.88 & 32.20 & Kırıldı \\
\hline 40 & 0.7 & 48.283 & 3.2 & 953.555 & 28.49 & 26.30 & Kırıldı \\
\hline
\end{tabular}

\section{Teşekkür (Acknowledgement)}

Bu çalışma Adnan Menderes Üniversitesi BAP projeleri MF-17022 ve MF-18004 kapsamında desteklenmektedir. 


\section{Çıkar Çatışması (Conflict of Interest)}

Yazarlar tarafından herhangi bir çıkar çatışması beyan edilmemiştir. No conflict of interest was declared by the authors.

\section{Kaynakça (References)}

Sain, T. and Narasimhan, R., (2011), Constitutive Modeling of Ice in The High Strain Rate Regime. International Journal of Solids and Structures, 48, 817-827.

Knight, C.A. and Knight, N.C., (1976), Hail Embryo Studies. International Conference on Cloud Physics, Boulder, Colorado. Boston, Mass. American Meteorological Society. United States.

Crenshaw, B.V. and Koontz, J.D., (2002), Hail : Sizing It Up !Western Roofing Magazine, 2-7.

https://www.iii.org/fact-statistic/facts-statistics-hail\#top

Uz ME, Yilmaz G, Bircan T (2017) The making of a hailstone simulated realistic damage. Journal of Engineering Sciences and Design 5(2):411-423. https://doi.org/10.21923/jesd.327312.

Uz ME, Teh L, Maguire J (2014) Developing Australia's first hailproof roofing profiles. Research case study. Open Days's poster, SBRC

Shi, M. F.; Brindza, J.; Michel, P.; Bucklin, P.; Belanger, P. and Prencipe, J., (1997), Static and Dynamic Dent Resistance Performance of Automotive Steel Body Panels. SAE Technical Paper.

Swift JM (2013) Simulated hail ice mechanical properties and failure mechanism at quasi-static strain rates. University of Washington, USA

Laurie JAP (1960) Hail and Its Effects on Buildings. vol 176. Research Report, NBRI, Pretoria, South Africa

Mcccormick, M.; Fekete, J.; Meuleman, D. and Shi, M., (1998), Effect of Steel Strengthening Mechanisms on Dent Resistance of Automotive Body Panels. SAE Technical Paper.11. Nelson S. P., (1983), The influence of storm flow structure on hail growth. J. Atmos. Sci.,40, 1965-1983.

Nomura, S.; Yutori, Y.; Iwaya, J.; Miyahara, M. and Kokubo, I.A., (1984), Study of the Dynamic Dent Resistance. 13th. Biennial Congress International Deep Drawing Research Group-Efficiency in Sheet Mental Forming.

Johnson, T.E. and Schaffnit, W.O., (1973), Dent Resistance of Cold-Rolled Low-Carbon Steel Sheet. SAE Technical Paper, 730528

Fleming, H.G.; Skarajew, M.; Szalla, (1997), J.A.G. A Laboratoy Dent Test for Outer Panel Steels.

Brimelow, J.C.; Reuter, G.W. and Poolman, E.P. (2002a): Modeling maximum hail size in Alberta thunderstorms. Wea. Forecasting, 17, 1048-1062.

Dunlop, S., (2008), Oxford Dictionary ofWeather 2nd Ed., New York: Oxford University Press

Flüeler, P.; Stucki, M.; Guastala, F. and Egli, T., (2008), Hail Impact Resistance of Building Materials Testing, Evaluation and Classification. 11DBMC International Conference on Durability of Building Materials and Components ISTANBUL. Turkey: Istanbul Technical University, Istanbul, Turkey.

https://agroinsurance.com/en/spain-hail-storms-in-province-of-alicante-cause-3-million-euro-worth-of-damage/ 